\title{
A comparison of constrained and random metric figures in paired-associates learning '
}

RICHARD A, KULP

HUTRRO DIVISION NO. 2 (ARMOR) FORT KNOX, KENTUCKY

The present study compared the use of constrained and random metric figures in a paired-associate leaming task. Both random and constrained (Redundancy-I) 4 by 4 metric figures were used as stimuli and were paired with numerals. In terms of correct anticipations, perceptual leaming with random figures was better than with constrained. Effects of interstimulus interval were found to be identical to those previously demonstrated in paired-associate learning situations. The results were discussed in terms of supporting and extending previous investigations in demonstrating the consistency of results when sampling rules for metric figures are employed.

Over the past 15 years, several approaches have been employed in an attempt to define the salient features of stimuli in visual form perception (e.g., Attneave \& Arnoult, 1956; Baker \& Alluis1, 1962; Michels \& Zusne, 1965). Through the various attempts at quantification of form dimensions, investigators have applied standard methods of generating figures in the hopes that one such method would accurately predict perceptual behavior. A considerable amount of research has been done with metric figures or "histoforms," that look like solidly contoured bar graphs (cf., Baker \& Alluisi, 1962; Fitts \& Leonard, 1957). The results of these studies have consistently demonstrated that perceptual recognition decreases as constraint (use of a redundant sampling rule) increases, and that performance efficiency decreases (i.e., response time and errors increase) with increases in the complexity of visual metric figures.

The purpose of the present experiment was to investigate the generality of the results obtained in previous studies using metric histoforms, with a slight modification of the stimuli and a different task-i.e., a paired-associates learning task. Previous studies have used various tasks, for example, standard speedof-identification task (Fitts \& Leonard, 1957) and paper-and-pencil cancellation task (Baker \& Alluisi, 1962).

\section{Method}

The experimental design was a 2 by 3 by 2 factorial with repeated measures over the last factor. The first factor consisted of two interstimulus intervals $\left(T_{8-s}, 5\right.$ and $\left.10 \mathrm{sec}\right)$; this is the time between the onset of a flgure and the onset of the next figure in sequence. The second factor consisted of three anticipation intervals $\left(\mathrm{T}_{\mathrm{B}-\mathrm{r}}, .5,1.5\right.$, and $\left.2.5 \mathrm{sec}\right)$; this is the time between the onset of a figure and the onset of its correlated response (R) numeral. The third factor was the constrained (redundant) and random figures.

Materials. Four-column metric histoforms were sampled from the 256 random (nonconstrained) and the 24 possible constrained figures (also referred to as "Redundancy-I" figures by Baker \& Alluisi, 1962) in the population. Random and constrained four-column metric histoforms are shown in Fig. 1A and 1B, respectively. Note that each possible column height appears once and only once in the constrained figure, and that the actual stimulus used was that of the steplike figure (solid line) and not the solidly contoured bar graphs used previously. For additional details on figure generating procedures, see Baker \& Alluisi, 1962.

A sample of four random metric histoforms was drawn at random to serve as stimulus figures in one condition, and a sample of four constrained metric histoforms was drawn at random from the 24 possible constrained histoforms for the second set of stimulus figures. The response items were numerals $0,1,2$, $3,4,6,7$, and 8 . Thus, the paired-associates consisted of eight figures paired with numerals.

Apparatus. The stimulus items were presented visually on a 10 in. rear projection screen by a Carousel slide projector (Model 800). A Diaco (Model R115) digital readout (one digit) presented the response digits to be paired with the appropriate stimuli. Four Hunter tumers (Model 111-C) were used in programming the materials. The rear projection screen and the digital readout were located on a vertically placed display panel approximately 28 in. from the seated S.

Procedure. Each $\mathrm{S}$ was seated facing the display panel with $E$ seated behind the display on S's right. The general procedure was the exposure of a fligure for $.5 \mathrm{sec}$ on the rear projection screen, followed by a delay of 0,1 , or $2 \mathrm{sec}$ (stimulus to response delay) before the presentation of the response numeral (exposed for 1 sec). The time between the onset of an $R$ numeral and the onset of the following figure (postanticipation interval $-\mathrm{T}_{\mathrm{r}-\mathrm{s}}$ ) was $4.5,3.5$, and $2.5 \mathrm{sec}$ in the $5 \mathrm{sec}$ $T_{\mathrm{S}-\mathrm{S}}$ condition and $9.5,8.5$, and $7.5 \mathrm{sec}$ in the $10 \mathrm{sec}$ $T_{S-S}$ condition. Thus, the $T_{S-s}$ intervals were varied by manipulating the $T_{r-s}$ intervals. All responses given by the $S$ during the stimulus duration or the stimulus-to-response lag $\left(\mathrm{T}_{\mathrm{S}-\mathrm{r}}\right)$ were recorded by $\mathrm{E}$. Each $S$ went through the list of eight figures 13 times; his first time through the list served as a familiarization block. In order to minimize the effects of serial learning, the block of eight pairs was randomized on each successive presentation. 
Subjects. The Ss were enlisted men assigned to duty at the US Army Armor Center, Fort Knox, Ky. A total of $60 \mathrm{Ss}, 10$ per experimental condition, were randomly assigned to the various experimental conditions.

\section{Results}

The means of the number of correct anticipations for the experimental groups are presented in Table 1. These values represent the total numbers of correct anticipations across all twelve presentations of the list.

An analysis of variance of these data indicated that the main effect of the constrained-random factor was statistically significant $(F=5.54, d f=1 / 54, p<.05)$, as was the $T_{s-s}$ factor $(F=5.30, d f=1 / 54, p<.05)$. The only interaction found to be statistically significant was that of $T_{s-s}$ by $T_{s-r}(F=3.43, d f=2 / 54, p<.05)$. This indicates that the number of correct anticipations in the two $\mathrm{T}_{\mathbf{s}-\mathrm{s}}$ conditions depends upon the level of $T_{s-r}$.

Discussion

With regard to the temporal factors investigated in the study, the results indicate: (a) The significant difference found between the two levels of $T_{\mathrm{S}-\mathrm{s}}(5$ and 10 sec) is consistent with the results of previous studies of time factors in paired-associate learning (e.g., Baker \& Noble, 1965); that is to say, they found that increases in the $\mathrm{T}_{\mathrm{r} \rightarrow \mathrm{s}}$ interval significantly increased learning. (b) The anticipation interval was not found to be a significant source of variation, whereas it had previously been found to be a relevant factor in pairedassociate learning (Baker \& Noble, 1965).

The results of the present study support and extend those of previous investigations (Alluisi \& Hall, 1965; Baker \& Alluisi, 1962; Thurmond \& Alluisi, 1967) in demonstrating that perceptual learning was greater with random than with constrained (Redundancy-I) figures. Thus the sampling rules used in generating the figures (which were modified from the contoured bar graphs used previously) significantly affected performance, as measured by the total number of correct anticipations.

Table 1

Mean number of correct anticipations on leaming list

\begin{tabular}{|c|c|c|c|c|c|c|}
\hline \multirow[b]{2}{*}{$T_{s-r}$} & \multicolumn{6}{|c|}{$T_{s-s}$} \\
\hline & $.5 \mathrm{sec}$ & $\begin{array}{r}5 \mathrm{sec} \\
1.5 \mathrm{sec}\end{array}$ & $2.5 \mathrm{sec}$ & $.5 \mathrm{sec}$ & $\begin{array}{l}10 \mathrm{sec} \\
1.5 \mathrm{sec}\end{array}$ & $2.5 \mathrm{sec}$ \\
\hline Constrained Figures & s 7.9 & 16.1 & 10.2 & 18.2 & 13.8 & 17.2 \\
\hline Random Figures & 9.6 & 18.8 & 10.8 & 18.7 & 15.7 & 17.9 \\
\hline
\end{tabular}
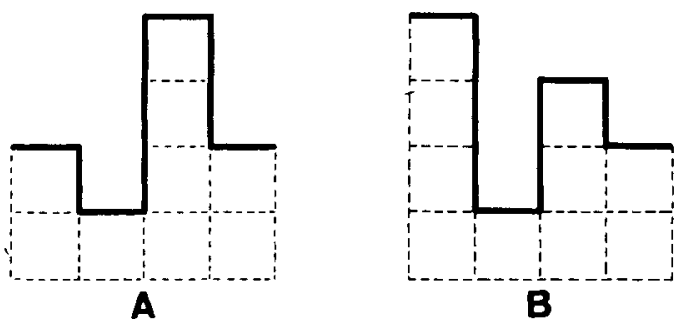

Fig. 1. Two figure generating methods from a 4 by 4 matrix: (A) random metric histoform, (B) constrained metric histoform. Dotted lines were not present in the actual stimulus but shown here for clarification.

It is clear that Redundancy-I is a kind of redundancy that hinders rather than helps man's perception of form, at least with noise-free figures. Alluisi (1960) has suggested that the Redundancy-I figures are more difficult to identify because they are more similar -i.e., because they form a more homogeneous subpopulation of figures than random metric figures of the same level of complexity. The data of the present study indicate that the Redundancy-I figures are more difficult to learn, in addition to their being more difficult to discriminate or match, as shown in the previous studies.

\section{References}

Alluisi, E. A. On the use of information measures in studies of form perception. Percept. mot. Skills, 1960, 11, 195-203.

Alluisi, E. A., \& Hall, T. J. Effects of transphenomenal parameter on the visual perception of form. Psychon. Sci., 1965, 3, 543544.

Attneave, F., \& Amoult, M. D. The quantitative study of shape and pattern perception. Psychol. Bull., 1956, 53, 452-471.

Baker, B. L., Noble, C. E. Effects of time factors in pairedassociate verbal learning. J. verbal Learn. verbal Behav., 1965, 4, 437-445.

Baker, E. J., \& Alluisi, E. A. Information handling aspects of visual and auditory form perception. J. engng. Psychol., 1962, $1,159-179$.

Fitts, P. M., \& Leonard, J. A. Stimulus correlates of visual pattern recognition-a probability approach. Wash. D. C., Off. Naval Res., Final Rep. of Contract Nonr-495(02), October, 1957.

Michels, K. M., \& Zusne, L. Metrics of visual form. Psychol. Bull., $1965,63,74-86$.

Thurmond, J. B., \& Alluisi, E. A. An extension of the informationdeductive analysis of form. Psychon. Sci., 1967, 7, 157-158.

\section{Note}

1. This research reported in this paper was performed by HumRRO Division No. 2 (Armor) Fort Knox, Kentucky, under Department of the Army contract with the George Washington University. The contents of this paper do not necessarily represent the official opinion of the Department of the Army. The author is indebted to Drs. Earl A. Alluisi and John B. Thurmond for their comments on this paper. 